\title{
Demand estimation of bus as a public transport based on gravity model
}

\author{
Noor Asmael ${ }^{*}$ and Mohanned Waheed $^{2}$ \\ ${ }^{1}$ Faculty of Engineering, Mustansiriyah University, Baghdad, Iraq \\ 2 Building and Construction Engineering Department,University of Technology, Baghdad, Iraq
}

\begin{abstract}
Bus as a public transport is a suitable service to meet the travel demand between any two zones. Baghdad faced with severe traffic problems along with the development in city size and economy. Passengers have to wait lots of time during commutation to work because of the serious traffic jams. In the last years, rate of car ownership has increased as income levels have gone up and cars have become a preferable mode of transport. Bus, as the only public mode of transport available, is suffering from inconvenience, slowness, and inflexibility. A big emphasis must be given to the public transport system because it introduces an active utilization of limited resources, energy and land. This study determines the demand of public routes for buses using boarding / alighting values to generate a model and assign these demand values to the bus network. Five public routes were selected to collect the required data. Ride check and Point check survey was conducted for each selected route. The results of this study were public demand assigned to the selected bus routes, dwell time, load factor and headway. It is observed that R1 and R3 have the heaviest travel demand; they need special study to improve bus performance and make better transit. The model developed with only limited data available to predict travel demand will assist transportation planners and related agencies in decision making.
\end{abstract}

\section{Introduction}

Baghdad, one of the most populated cities in Iraq with a population of about 7.5 million in 2016 according to AL-Khatib and Alami in 2012 [1]. So it is important to provide enough public transport as sustainable modes to overcome traffic problems. Public transport is very important in Iraq; not only to fulfills the mobility demand in a growing city, but a bigger share of bus mode have positive effects including decrease in pollution, private mode share and energy. When more people travel by public bus transport, it leads to less people travelling by other modes. Thus, road congestion eventually decreases, road safety increases and fuel cost decreases.

Transportation demand has increased quickly in urban areas due to rapid population growth and alteration in travel patterns. It is encouraged to plan bus systems to meet the needs of users and service providers within the limited resource constraints [2]. For the proper functioning of the transportation network, it is important that demand and supply for mobility are aligned properly [3]. Estimates of bus passenger demand have always been important to bus operators and to transport planners [4]. Prediction of public demand using conventional transportation models has disadvantages, as they need huge data and are unable to deal with changes in generation rates. This has led to the need for a quick, simple model with low cost to inspect different public transport alternatives [4].

The bus planning process is a very complex process that contains five activities: Network Design, Setting Frequencies, Timetable Development, Bus Scheduling and Driver Scheduling [5]. The bus demand is affected mainly by spatial factors, such as the existence of the central business district (CBD), shops, educational institutes, and offices. These important spatial facilities attract many passengers [6]. Very few works concentrated on predicting demand on bus routes, some of these works can be abstracted as follows:

Gahlot et al [7] presented a GIS based methodology for selection of BRT alignment. The spatial distribution of transit trips is considered the base for selection of a BRT corridor in the city for the target year. The developed model utilizes transit trip, land use and the demographic characteristics to select the high BRT ridership corridor. Jäger et al [8] introduced a method to analyze taxi systems and forecast a model to predict the taxi demand. Siridhara [9] investigated public transportation in Greater Nakhon Ratchasima using service characteristics, quality, mode share and ridership. His work identified the current mode share and the effect of public transport role to other modes. Kalaanidhia and Gunasekaran [10] evaluated the urban transportation accessibility and its effect on 
the ridership of the bus system. They focussed to demonstrate accessibility Indices, which can assist in evaluating the transit facilities. Carpio-Pinedo [11] used multiple linear regressions to forecast bus demand model at a stop level. Bus ridership is predicted using spatial variables, urban environment and network accessibility indicators. Simon and Furth [12] generated route origin/destination matrix from boarding/alighting data and was compared to actual O-D data. This method is recommended as simple, and inexpensive method of developing route O-D matrices. AlSahili $\bullet$ and Sadeq [13] try to study intercity bus $^{\bullet}$ demand, evaluate current services, $^{\bullet}$ and forecast future $^{\circ}$ bus $\bullet^{-}$ridership the Palestiniancity. A relatioship was established between $\bullet$ public demand $\bullet$ and $\bullet$ socioeconomic, $\bullet$ operating $\bullet$ variable s. They found variables obtained from onboard• survey• of $\bullet$ bus $\bullet$ riders which influence ridership demand. Li et al [14] try to forecast ridership at station level using back propagation neural network and use a new predictor like population per distance band. The result of their study leads to the adequacy of the proposed models. Zhou et al [15] present research to forecast passenger bus demand by utilizing three models: weighted time varying poisson model, autoregressive integrated moving average and time varying poisson model. Smit [6] develop bus demand models using traditional four step model which included trip generation, distribution and assignment models. Herijanto and Thorpe [16] concluded that when there is attention to the quality and quantity of trip attraction data, then the combined application between singly constrained gravity model and fluid analogy has considerable power in developing countries. Asmael [17] develops an O-D trip matrix between bus terminals based on GIS in Baghdad city and try to suggest future scenarios alternative to meet the requirements of future demand.

\section{Field survey types}

\subsection{Ride check survey}

It is one of techniques used to provide information on passenger load along transit routes. Boarding and alighting is the main data source of this survey. A surveyor travels during the journey of the bus and write the number of boarding and alighting values, dwell time, and the number of passengers on board for every stop. This survey provides an actual service route; journey time and average speed.

Ride check survey includes boarding and alighting counting to observe the change in load profile and estimate load factor. Load profile enables the planner to monitor variation in the load over the transit stops [18]. Load factor equals to the values of "passenger-km" divided by the "capacity-km". Load factor gives information about the effectiveness and service frequency of the bus route. The survey gives information based on demand characteristics to determine which stop can be eliminated or relocated along transit routes. From the ride check survey, dwell time can be estimated at each stop. Dwell time is interval time measured at a bus stop when the bus stops for boarding and alighting passengers [19].

\subsection{Point check survey}

It is one of data collection methods used to provide information on load at specific points along the transit route. From ride check survey results, it can determine the position of maximum load point along each route, which represents the input to point check survey. The data recorded in point check survey include route name, vehicle number, passenger load and vehicle capacity. Then average load per route is determined by analyzing the load of various buses and aggregating by time periods.

\section{Data collection}

Baghdad is the study area of this work. It has the largest concentration of urban population in Iraq. It is the center of Iraq's finance, commerce, and manufacturing. Public transport is the only means of transport for a large segment of population in Baghdad. Most public bus routes are centralized in the main CBD areas, buses travel along the fixed routes and stop at every bus stop according to demand. Five public routes were selected that travel inside the city center. Table (1) and Figure (1) show public routes selected for data collection:

Table 1. Five bus public routes selected

\begin{tabular}{|l|l|}
\hline Route Name & Route symbol \\
\hline Bab- Moatham - Shaab & R1 \\
\hline Bab- Moatham - 7Ebkar & R2 \\
\hline Mawwal- Aden Square & R3 \\
\hline Hay-AlJameah- Bab- Moatham & R4 \\
\hline Bayyaa- Bab- Moatham & R5 \\
\hline
\end{tabular}

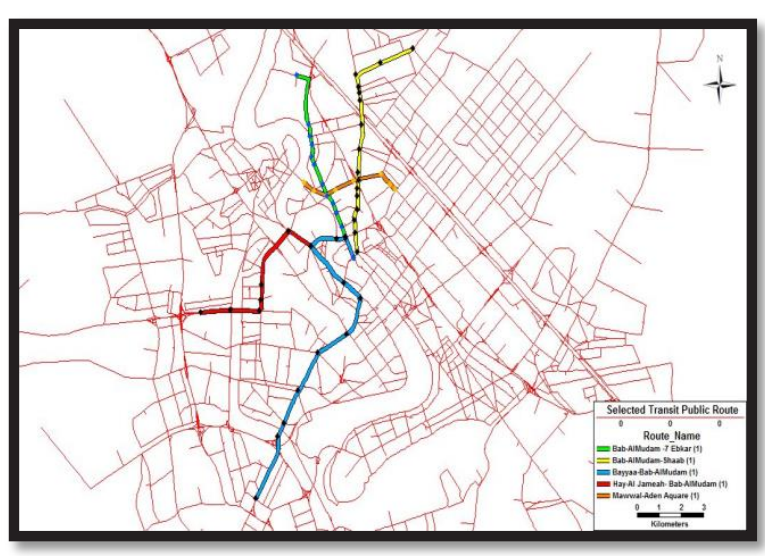

Fig. 1. Selected five bus public routes 
For each route, ride and point check was conducted. For ride check survey, two observers were riding two vehicles in the same period. The observer was seated at the end of the vehicle for clear vision. When passengers get on/off the bus, the observer records number of boarding and alighting for each stop. For point check survey one observer is sufficient to count passenger at each stop. Only the number of passengers and number of vehicles at specific stops is counted. The travel time, dwell time, boarding and alighting count, number of vehicles were recorded in two peak hours, the first peak hour was from 8-9 AM and the second peak hour was 2-3 PM for three typical days.

\section{Generation origin-destination based on gravity model}

Conventional transportation models require big data collection for predicting public transport demand, which include expensive surveys, and gathering data specific to public transport and road networks. The generated models give inaccuracy in predicting transit demand. Therefore, there is a need for simple, inexpensive method to predict transit demand, and using the OD data from on/ off data, it is able to determine passenger loads and assignment flows on the transport network. If number of transit trips in a certain stop are known, then each origin to each destination trip can be determined. This can be done using a gravity model, which uses the distance between zones and the number of trips from and to the stops to estimate the number of trips between the stops. The gravity distribution model was calibrated to find number of passengers for each bus stop pair with a direct connection. To generate (origindestination) transit matrix, then at each bus stop, the number of boarding and alighting was entered. Load between all stops are computed in this step and are used to generate an Origin-Destination matrix which gives an overview of how many trips from each stop to all other stops are undertaken.

\section{Results and analysis}

The following represent data results of this work:

\subsection{Determination of bus route attributes}

Table (2) shows summary of data analysis for five selected bus public routes. Headway is the difference in time between two vehicles arriving at a specific stop. It represents an important factor to identify transit service reliability [20].

Table 2. Summary of route data analysis

\begin{tabular}{|c|c|c|c|c|c|}
\hline $\begin{array}{l}\text { Route } \\
\text { Symbol }\end{array}$ & $\begin{array}{c}\text { Travel } \\
\text { Time } \\
\text { Min. }\end{array}$ & $\begin{array}{c}\text { Distance } \\
\text { Km }\end{array}$ & $\begin{array}{c}\text { Dwell } \\
\text { Time } \\
\text { Sec. }\end{array}$ & $\begin{array}{c}\text { Headway } \\
\text { Min. }\end{array}$ & $\begin{array}{c}\text { Load } \\
\text { Factor }\end{array}$ \\
\hline R1 & 38 & 11 & 17 & 0.4 & 0.7 \\
\hline R2 & 24 & 8.5 & 11 & 5 & 0.57 \\
\hline R3 & 14.5 & 4.6 & 16 & 0.9 & 0.65 \\
\hline R4 & 35 & 10 & 9 & 3 & 0.5 \\
\hline R5 & 56.5 & 15 & 17 & 1.4 & 0.55 \\
\hline
\end{tabular}

\subsection{Route load profile analysis}

For trip assignment, the shortest path method was used and the following Figures from (2) to (6) show a trip assignment for each bus public route selected during peak hour.

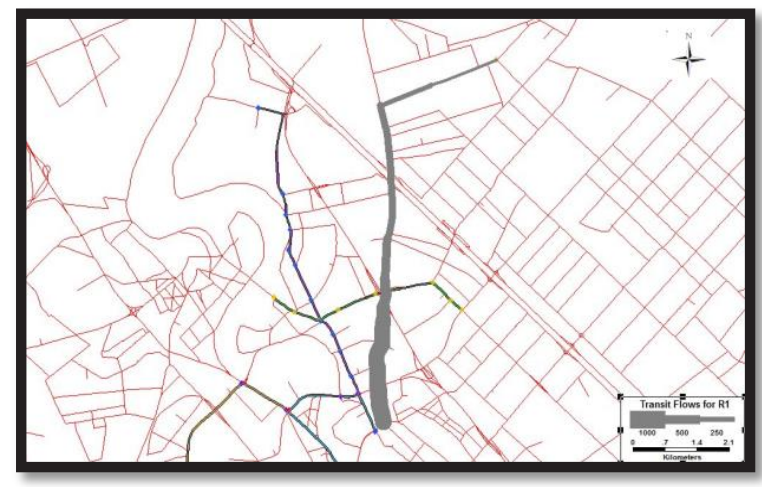

Fig. 2. Trip assignment for Bab- Moatham - Shaab route. 


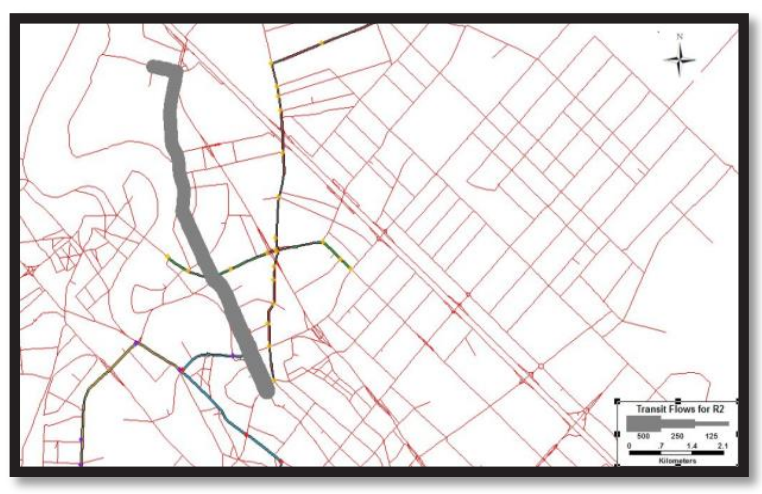

Fig. 3. Trip assignment for Bab- Moatham - 7Ebkar route.

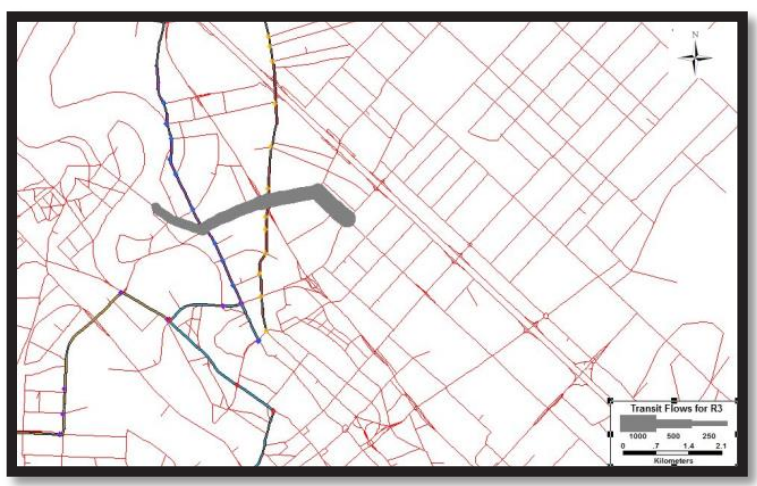

Fig. 4. Trip assignment for Mawwal- Aden Square route.

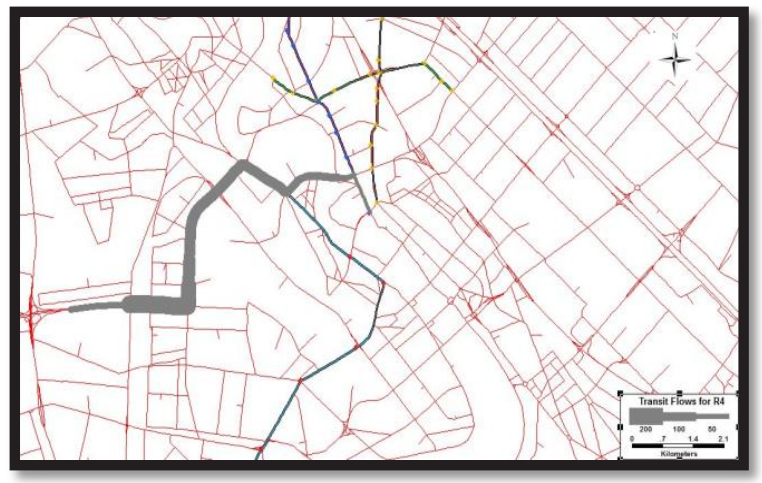

Fig. 5. Trip assignment for Hay-AlJameah- Bab- Moatham route.

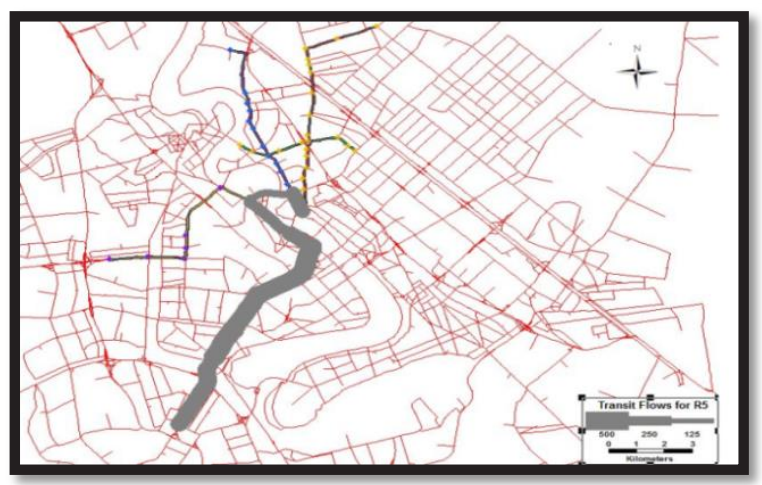

Fig. 6. Trip assignment for Bayyaa- Bab- Moatham route.

\subsection{Boarding and alighting profile analysis}

The following Figure(7) shows the results of boarding / alighting count for each bus stop for five selected bus public routes.

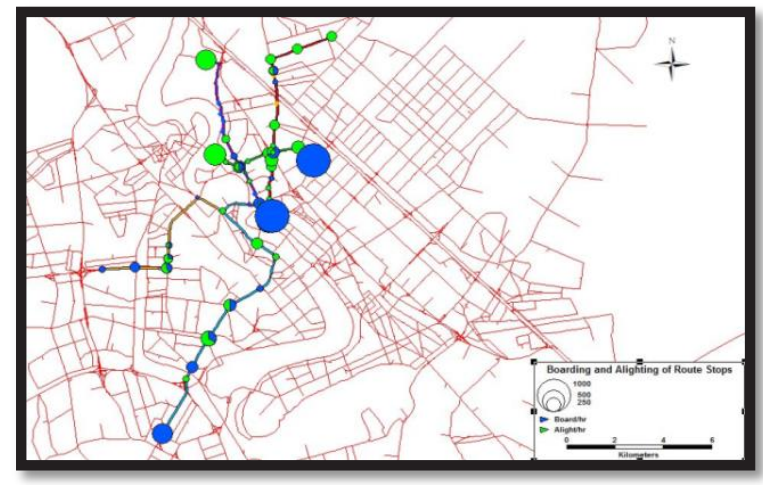

Fig.7. Boarding / alighting count of route stops.

\subsection{Determination of bus demand routes}

From trip assignment results the following table (3) represents demand for each bus public route.

Table 3. Demand for bus public routes

\begin{tabular}{|c|c|}
\hline Route Symbol & Demand (Passenger per hour) \\
\hline R1 & 2552 \\
\hline R2 & 1778 \\
\hline R3 & 2364 \\
\hline R4 & 407 \\
\hline R5 & 1392 \\
\hline
\end{tabular}

From the table results, it is shown that $\mathrm{R} 1$ and $\mathrm{R} 3$ have the heaviest demand along route, these results are consistent with assignment results of origindestination matrix developed by [21].

\section{Conclusions}

Ridership analysis represents an important role in providing best transit service and evaluates financial profit for transit agencies. The count of boarding and alighting passengers can provide useful information for planners to determine the bus demand for every public route. Accordingly, improve transit operational strategies. Some of these strategies include increasing or decreasing daily vehicles and or increase/reduce headway to satisfy transit demand. Stop level ridership provides information for planners to identifying the most bus stops with a large number of boarding, and then adjust transit service to meet transit demand to achieve better service quality. This work uses limited 
data to estimate public demand. The developed model with only limited data provides a good way of estimating public demand based on a stop level and aids in identifying potential future adjustments and the required fleet size. This is a flexible method and easily available data provide a way to improve transit operation to meet transit demand and to achieve better service quality and then to encourage people to use public transport.

\section{References}

1. AL-Khatib and Alami, Baghdad Comprehensive city development plan, Report, Amanat Baghdad, Iraq (2012)

2. M. Advani and G. Tiwari, Indian J. Transp. Manag. 30, 4, pp. 363-391, (2006)

3. E. Klok, Determinants of the demand for bus transport, Master Thesis, University of Twente, (2010)

4. P. Mullen, Transportation (Amst)., 4, 3, pp. 231252, (1975).

5. A. Ceder and N. Wilson, Transp. Res. Part B: Methodological 208,4, (1986)

6. Marijn Smit, Exploring the demand for bus transport, Master Thesis, University of Twente, (2014)

7. V. Gahlot, B. L. Swami, M. Parida, and P. Kalla, Int. J. Sustain. Built Environ., 1, 1, pp. 102-109, (2012)

8. B. Jäger, M. Wittmann, and M. Lienkamp, J. Traffic Logist. Eng. 4, 2, (2016)

9. S. Siridhara, J. Traffic Logist. Eng., 2, 2, pp. 120-125, (2014).

10. S. Kalaanidhi and K. Gunasekaran, Procedia Soc. Behav. Sci., 104, pp. 885-893, (2013)

11. J. Carpio-Pinedo, Procedia - Soc. Behav. Sci., 160, pp. 205-214, (2014).

12. B. J. Simon and P. G. Furth, J. transp. Eng., 111, 6, pp. 583-593, (1985)

13. K. Al-Sahili and A. Sadeq, J. Public Transp., 6, 2, pp. 19-35, (2003)

14. J. Li, M. Yao, and Q. Fu, Discret. Dyn. Nat. Soc., 2016,(2016)

15. C. Zhou, P. Dai, and R. Li, Proc. - IEEE 13th International Conference on Data Mining Workshops, pp. 1069-1076, (2013)

16. W. Herijanto and N. Thorpe, J. East. Asia Soc. Transp. 6, pp. 1708-1723, (2005)

17. N. Asmael, Int. Res. J. Eng. Technol. 3,10, pp. $1-5,(2016)$

18. A. Ceder, Public Transit Planning and Operation: Theory. Modeling and practice. 0xford: Elsevier, (2007)

19. V. Vuchic,Urban transit: operations, planning, and economics, (2005)

20. C. Liao, and H. Liu, Transp. Res. Rec. 2143,34 43,(2010)

21. N. Asmael,A GIS-Assisted Optimal Route Selection Based on Transportation Network
Design (Baghdad Metro Case Study), Ph.D Thesis, University of Baghdad (2015) 